\title{
Artificial Intelligence and the Academy's Loss of Purpose
}

\author{
Anthony G. Picciano \\ City University of New York Hunter College and Graduate Center
}

\begin{abstract}
This article speculates on the future of higher education as online technology, specifically adaptive learning and analytics as infused by artificial intelligence software, develops and matures. Online and adaptive learning have already advanced within the academy, but the most significant changes are yet to come. These evolving technologies have the potential to change the traditional roles in our colleges and universities to the point that many educators will reconsider their purposes as teachers, researchers, and administrators.
\end{abstract}

Keywords: artificial intelligence, online education, adaptive learning, analytics, online learning, blended learning, higher education, the future

Picciano, A.G. (2019). Artificial intelligence and the academy's loss of purpose. Online Learning, 23(3), 270-284. doi:10.24059/olj.v23i3.2023

\section{Artificial Intelligence and the Academy's Loss of Purpose}

In February 2019, an article in the New York Times described a global competition that hundreds of scientists enter every two years called the Critical Assessment of Structure Prediction (Metz, 2019). Referred to as the "World Cup" of biochemical research, teams of scientists tackle a biological puzzle called "the protein folding problem." Essentially, they try to predict the threedimensional shape of proteins in the human body, a problem that no one has ever been able to solve. Past winners have chipped away at it, but a solution still eludes the scientific community. In 2018, the contest was not won by academics. It was won by a team at DeepMind, the artificial intelligence (AI) lab owned by Google's parent company, Alphabet, Incorporated. In describing DeepMind's accomplishment, Mohammed AlQuraishi, a biologist at the Harvard Medical School, who has dedicated his career to protein research, commented that he felt "a melancholy" after losing to DeepMind. "I was surprised and deflated. They were way out in front of everyone else." He criticized big pharmaceutical companies like Merck and Novartis, as well as his academic community, for not keeping pace. "The smartest and most ambitious researchers wanting to work on protein structure will look to DeepMind for opportunities" (AlQuraishi, 2018). He urged the life-sciences community to shift their attention toward the kind of AI work practiced by DeepMind. 
DeepMind's victory predicted the future of biochemical research, increasingly driven by machines and the people who oversee them. Another researcher, Derek Lowe, said "It is not that machines are going to replace chemists. It's that the chemists who use machines will replace those that don't'" (Metz, 2019).

AI development of this magnitude requires enormous amounts of data. DeepMind can lean on the massive computer data centers that underpin Google as well as many of the world's top AI researchers, who know how to get the most out of these facilities. "It allows us to be much more creative, to try many more ideas, often in parallel," said Demis Hassabis, the chief executive and a cofounder of DeepMind (Metz, 2019). Universities and big pharmaceutical companies are unlikely to match these resources.

Kai-Fu Lee, a former senior executive at Google and Microsoft, stated that humanity is moving towards the establishment of a "new world order" dominated by AI, cloud computing, and robotics that will have significant ramifications for many aspects of human endeavors (Lee, 2018). How will our species respond? Lee believes that many workers will experience a "psychological loss of purpose" as AI changes the nature of their occupations (Lee, 2018, p. 21). A more pessimistic prediction comes from Yuval Noah Harari, bestselling author of Sapiens, who commented that AI has the potential to create a "useless class of superfluous people" (Harari, 2017, p. 322). The term "useless class of superfluous people" surely attracts attention, but it may be a bit extreme. In a later book, Harari takes a more moderate stand and discusses at length the merging of workers with large-scale integrated digital networks (Harari, 2018, p. 22). There are no firm estimates of the number of jobs in this country that will be displaced by AI and other forms of automation. While one estimate suggests $47 \%$ (Frey \& Osborne, 2013), another poses 38\% (Berriman \& Hawksworth, 2017), and yet another puts it as low as 9\% (Artnz, Gregory \& Zierahn, 2016). The fact is that no one really knows. One aspect of this displacement is certain: Many of these displaced jobs will be in white collar and professional areas, such as teaching, law, and medicine as well as the corporate sector.

It is not the purpose of this article to review this issue as it relates to the entire human race but to speculate specifically on the future of higher education as online technology, such as AIinfused adaptive software and analytics, changes the traditional role of educators in our colleges and universities. Online and adaptive learning have already advanced within the academy, but the most significant changes are yet to come.

\section{Online Education Has Already Made Significant Progress in Higher Education}

Overall enrollments at colleges and universities have seen a small decrease in recent years, leveling off at about 20 million students. As of fall 2016, there were 6,359,121 students taking at least one fully online course, comprising $31.6 \%$ of all higher education enrollments. Furthermore, the percentage of higher education students taking these courses keeps increasing every year. It stood at $25.9 \%$ in 2012, at $27.1 \%$ in $2013,28.3 \%$ in 2014, and $29.7 \%$ in 2015 (Seaman, Allan, \& Seaman, 2018). For the purpose of their study, Seaman, Allan, and Seaman defined a fully online course as one where $80 \%$ or more of the seat time was replaced by online activity. The word blended was used to designate courses where some percentage of seat time (less than 80\%) was conducted online. Web-enhanced courses were defined as courses that have substantial Internetbased activity but do not necessarily replace seat time with time online. Although there is no exact count, it is estimated that there are millions of students taking these blended and Web-enhanced courses. Almost every college and university has acquired or contracted for a course or learning 
management system or platform. Soon most courses will have some Internet components, ranging from being fully online to being blended to having Web-enhancements. In a mere 25 years, online education has become integral to the delivery of instruction and no longer a novelty. As Larry Ellison, the founder and CEO of Oracle Corp., has often been quoted as saying "The Internet changes everything, I really mean everything" (as quoted by Schlender, 1999).

The pedagogical models being used in online education today range widely. Highly interactive models (teacher-student, student-student, student-course material) are very popular. Asynchronous (blogs, discussion boards, wikis) as well as synchronous communications (video and voice conferencing) are common. Furthermore, faculty and instructional designers integrate and blend these models to provide a variety of course activities. These models remain highly dependent upon teachers to guide, direct, and facilitate instruction. They generally are not more cost-efficient than traditional face-to-face instruction unless full-time faculty are replaced by contingent faculty. Recently, adaptive or personalized learning, which combines programmed instruction and learning analytics, is expanding and receiving a good deal of attention. Adaptive learning takes advantage of learning analytics and rudimentary AI software to monitor student progress and performance very closely and is consequently able to provide timely adjustments to the presentation of instructional material. Adaptive learning systems are customized to the personal needs of each student, which is why they are frequently referred to as personalized learning systems. As described by the EDUCAUSE Learning Initiative,

Adaptive learning is one technique for providing personalized learning, which aims to provide efficient, effective, and customized learning paths to engage each student. Adaptive learning systems use a data-driven - and, in some cases, nonlinear-approach to instruction and remediation. They dynamically adjust to student interactions and performance levels, delivering the types of content in an appropriate sequence that individual learners need at specific points in time to make progress. These systems employ algorithms, assessments, student feedback, instructor adjustments/interventions, and various media to deliver new learning material to students who have achieved mastery and remediation to those who have not. (Moskal, Carter, \& Johnson, 2017)

It should also be mentioned that adaptive learning is not new but can be traced back to the computer-assisted instruction (CAI) work of B. F. Skinner and Patrick Suppes in the 1950s and 1960s. However, the technology back then was very rudimentary compared to what exists today with high-speed Internet communications and advanced multimedia that can be delivered to homes, businesses, and mobile devices.

Depending upon the course design, adaptive learning can minimize the amount of interaction between the teacher and student and instead allow the software to deliver and monitor much of the course content. Learning analytics software monitors student progress and controls the pace of content delivery accordingly. Increasingly adaptive technology minimizes the faculty role in teaching and instead expands their role as tutor. The "faculty as tutor" model has been evolving as online learning has become more prevalent. Colleges with extensive experience in fully online academic programs, such as Athabasca University, the University of Phoenix, and Western Governors University, have promoted a model in which a master teacher administers a fixed curriculum with contingent faculty serving as guides and tutors for students. Contingent faculty have little discretion to modify or customize the curriculum or syllabus and follow a carefully developed script. In an adaptive course, all content, assignments, and assessments are delivered by the software. The adaptive model will become more prevalent in the future and may 
even come to dominate much of higher education because of its cost-effectiveness rather than its pedagogical value. Early research does suggest, however, that student learning outcomes are comparable to other formats (Dziuban, Moskal, Parker, Campbell, Colm, \& Johnson, 2018; Dziuban, Moskal, \& Hartman, 2016).

Of all the online learning models, the adaptive learning model has become the focus of a good deal of investment by corporate America and venture capital. Educational software companies that develop adaptive learning, such as Knewton, are raising tens of millions of investment dollars to develop new products (Wan, 2018). This type of investment is not common in the other types of teaching and learning models. To the contrary, the development of other models relies heavily on college-based faculty and instructional designers, many of whom have modest resources at their disposal. Eventually, the well-financed adaptive course development will likely win out. While adaptive learning integrated with learning analytics is in its early stages, it will continue over the next decade to change the way most teaching and learning is conducted in higher education.

\section{Two Futures-One Evolutionary and the Other Profound!}

Any attempt at predicting the future is based on calculated speculation. What will happen is difficult enough, but when it will happen is even more difficult. Niels Bohr, the Danish physicist, was said to have been fond of saying that "prediction is very difficult, especially if it's about the future." While he did not originate this quote, he fervently believed it. This article speculates about the future of American higher education in two periods: one over the next decade or so and the other in the 2030s and beyond. The latter will see major new technological developments bringing profound changes to our colleges and universities and presenting dilemmas for educators regarding their purpose and their role in the academy.

Over the next decade, digital technologies will advance in the development of manmachine interfacing or the ability of digital technology to interact with and assist in human activities. Figure 1 provides an overview of the major technologies presently in various stages of development and evolution. Nanotechnology and quantum computing form the base for the development of man-machine interfaces, such as AI, biosensing devices, robotics, and supercloud computing. In the 2020s these technologies will be more visible, but in the 2030 s and beyond they will begin to mature, integrate, and have their greatest impact. Robotics will play a major role in reshaping commercial, industrial, and manufacturing processes, while biosensing will do the same for medical and health services. For the purposes of adaptive learning, the supercloud and AI are most important and will be the focus of the remainder of this article. 


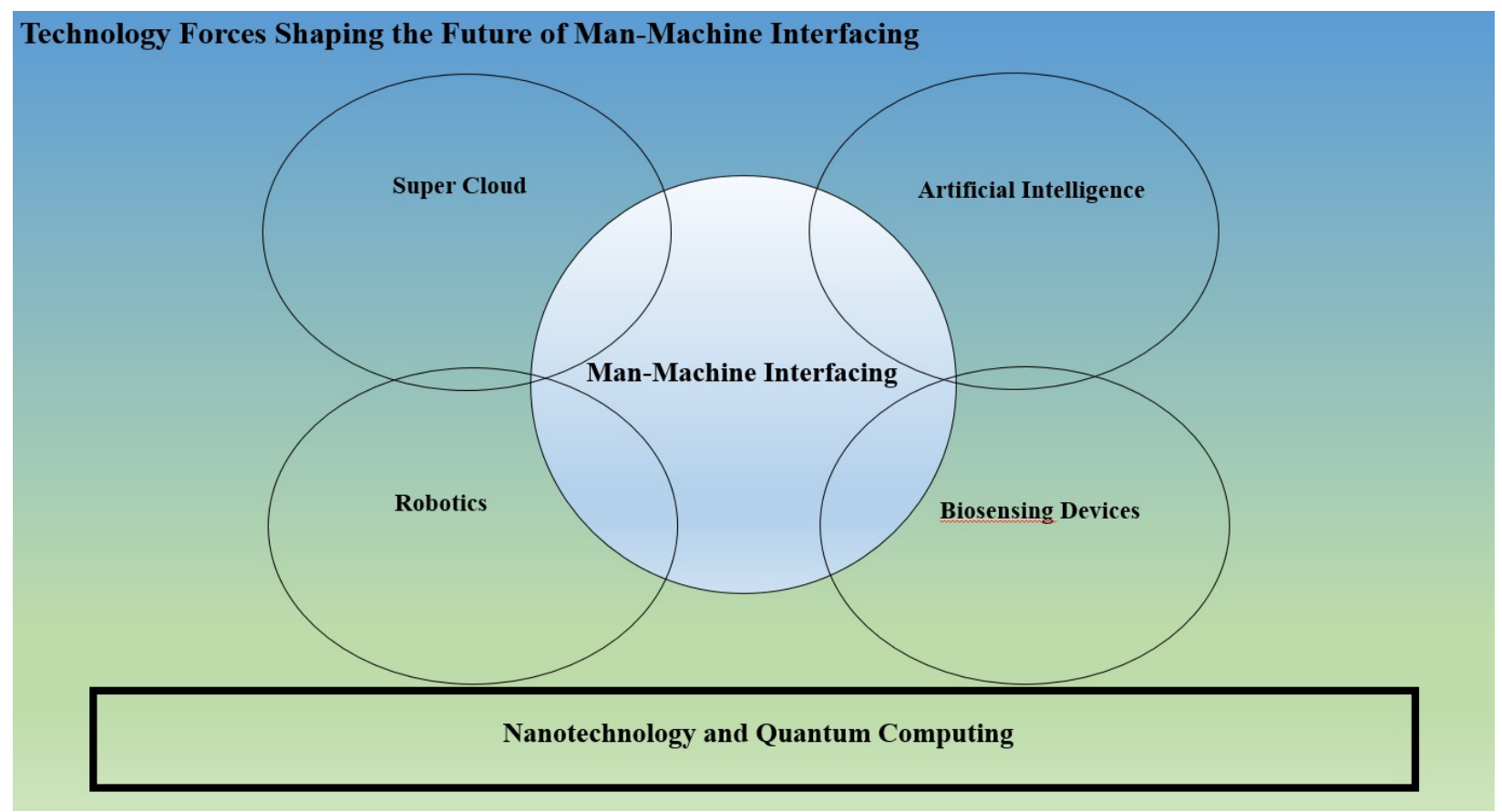

Figure 1. Technology Forces Shaping the Future of Man-Machine Interfacing.

Nanotechnology and quantum computing. Nano refers to a billionth of a meter, or the width of five carbon atoms. The simplest definition of nanotechnology is technology that functions at very close to the atomic level, and governments around the world have been investing billions of dollars to develop applications using it. These applications, for the most part, have focused on areas such as medicine, energy, materials fabrication, and consumer products. However, companies such as Intel and IBM have been developing nanochip technology, which has the potential to change the scope of all computing and communications equipment. IBM, for instance, announced in July 2015, a prototype chip with transistors that are just 7 nanometers wide, or about $1 / 10,000$ th the width of a human hair (Neuman, 2015). Nanochip technology is here now and is developing into commercial production and application. By the 2020 s, it will become a mature technology.

By the 2030s, the whole concept of a digital computer may give way to a quantum computer that operates entirely on a scale the size of atoms and smaller. Another decade or so of research and development on quantum computers may find their speed thousands of times faster than the speed of today's supercomputers. The storage capacity of such equipment will replace the gigabyte $\left(10^{9}\right)$ and terabyte $\left(10^{12}\right)$ world of today with zettabyte $\left(10^{21}\right)$ and yottabyte $\left(10^{24}\right)$ devices. Large-scale digitization of all the world's data will occur with access available on mobile devices. And all this technology and computing power will eventually be less expensive than it is now. Nanotechnology and quantum computing will provide the underlying base for the development of a host of new applications using AI and supercloud computing. The first generation of quantum computers will likely be available via the supercloud and geared to specific applications related to large-scale, complex research in areas such as neuroscience, NASA projects, DNA, climate simulations, and machine learning. 
Supercloud computing and education resources. In 1994, I described a place called Futuretown, where in the year 2025 people would be served by an all-inclusive Communications and Computer Services Utility (Picciano, 1994). This digital utility would provide all services related to computer, television, communications, and transaction processing, and it would be a one-stop facility for all information and entertainment services. Government, corporate America, hospitals, schools, and colleges would all use this utility for their operations. We have not quite developed this utility, but we are moving in that direction. Services provided by companies such as Optimum and Verizon already integrate data, voice, and video entertainment but are not there yet regarding transaction processing. When this prediction was made in 1994, the Internet and World Wide Web were in their nascent stages of development. There were few applications available other than file transfer (ftp), email, and electronic messaging. Home access was nonexistent in most parts of the country, and where it was available, users relied on low-speed dial-up modems. While there were some limited facilities for uploading and downloading images, video was impossible due to these low-speed connections. This began to change as higher speed connectivity became available via cable modems, fiber optics, and digital subscriber lines (DSL) in the early 2000s. With the improvement in the speed and quality of connectivity, cloud computing (or simply "the cloud") evolved, wherein users relied less on their personal computers for storing files and running programs. Cloud computing services became available through major companies, such as Google, Amazon, and Microsoft. Best-selling author Nicholas Carr described cloud providers as having turned data processing into utility operations that "allow vast amounts of information to be collected and processed at centralized plants" and fed into applications running on smartphones and tablets (Carr, 2014, p. 194). Essentially, cloud services can take responsibility for all file handling and storage as well as applications such as email, text messaging, and social networking. It is likely that a cloud-based database establishing a national registry of all citizens in the United States will be created similar to ones in Sweden and several other European countries. All of a Swedish citizen's medical and education information, for instance, is maintained on the national registry database. All Swedish citizens also are assigned a personal identification number (PIN), which is keyed to the national registry database. The PIN is then used for a host of services in medicine, banking, purchasing, and education. With advances in nano- and quantumcomputing technology, cloud computing will expand significantly to the supercloud and provide the database, communications, and computing capacity needed to perform most daily functions.

On the education front, cloud computing is just beginning to make inroads. While there has been movement to low-cloud applications, such as personal email, and middle-cloud applications, such as course and learning management systems, mission-critical applications, such as student or financial database systems, are still mostly maintained locally by colleges (Green, 2015). By the end of the 2020s, it is likely that the supercloud will have evolved to provide most digital services to all of education. By then, there will be little need for colleges to maintain their own administrative databases or course/learning management systems, and the implications of cloud computing will be significant, especially for instructional course development.

First, students and faculty will be able to access large numbers of courses and course materials developed by other faculty or commercial developers. We are seeing this now in the open educational resources (OER) movement, but an efficient and all-inclusive file-sharing system does not presently exist. While some websites and services assist with this, most course materials still reside on school- or campus-based computer systems with restricted access. Furthermore, since many faculty customize their materials to their own courses, they are not thinking about the convenience that sharing with others would provide. 
Second, the MOOC movement allowed for high investment in course development. A single course might cost $\$ 1$ million or more to develop and make available to a customer base. At most colleges this type of funding and investment in course development is a rarity, but it is beginning to catch on, usually in partnership with private enterprise. Some of the materials, especially media files, are very well done and are attracting faculty who use them for their own non-MOOC courses. The MOOC courses also integrate state-of-the-art features, such as adaptive/personalized learning, learning analytics, and micro assessments.

Third, MOOC-type materials are setting a standard for high-quality course content development that may in fact be leading to course standardization. This is especially true for introductory and gateway required courses that make up large portions of the curriculum. If all this course development is moved away from private developers and onto computer facilities in the supercloud, the ease with which faculty and students can access course material will increase tremendously. It is not unfathomable to think that there will be great pressure both inside and outside education to make use of these course materials. Policy makers who seek standards and promote common assessments will material available readily accessible to them in the supercloud. Perhaps most importantly, students also will have access to these courses and materials and will be able to develop their own programs of study with or without the guidance of faculty mentors and advisers. The ready availability of these courses will also raise important questions as to the credentialing of students, specifically as to whether only a traditionally accredited college or university can award a degree or certificate of completion.

Artificial intelligence and adaptive learning. Learning analytics software is still in its developmental stages but is gaining traction as an important facility for teaching and learning. This software increasingly depends upon AI techniques that use algorithms to understand instructional processes. The software also relies on large amounts of "big" data to build a series of decision processes. Significant increases in the speed and storage capabilities of computing devices that will be possible through nano and quantum technology will also increase the capabilities and accuracy of AI-driven learning analytics software. What is presently known as big data will be small in comparison to the "superbig" data that will be available with quantum computer systems.

AI allows learning analytics to expand in real time to support adaptive and personalized learning applications. For these applications to be successful, data must be collected for each instructional transaction that occurs in an online learning environment. Every question asked, every student response, every answer to every question on a test or other assessment is recorded and analyzed and stored for future reference. Software to grade essays and unstructured written assignments has also been evolving for several years (Markoff, 2013). While this approach is controversial, several states, such as Ohio and Utah, as well major companies, such as Education Testing Service and EdX, are moving to "robo-grading" and "e-rating" of essays (Smith, 2018; Ford, 2015, p. 130-131). As a result, complete evaluations of individual students as well as entire classes are becoming more common. Alerts and recommendations can be made as the instruction proceeds within a lesson, from lesson to lesson, and throughout a course. Students can receive prompts to assist in their learning, and faculty can receive prompts to assist in their teaching. By significantly increasing the speed and amount of data to be analyzed through nano- or quantum technology, the accuracy and speed of adaptive or personalized programs will be improved. Faculty will make inquiries about individual students to understand strengths and needs. They will be able to use an "electronic teaching assistant" to determine how instruction is proceeding for individual students and the class as a whole. They will be able to receive suggestions about 
improving instructional activities. Most AI applications in use today, and for the near future are narrow in their application and focus on a specific activity. In the years to come, broader purpose AI will evolve that will be applied to a variety of activities.

Lee (2018) classifies AI into five technologically sophisticated stages as follows:

1. Internet AI - makes recommendations based on Internet activity (i.e., Amazon);

2. Business AI - uses data that companies and other organizations routinely capture for commercial and procedural activities to make predictions (i.e., bank loan approval, insurance fraud, medical prognosis);

3. Perception AI - uses data from the physical world to make predictions using sensors and smart devices (i.e., weather, traffic flow, facial recognition)

4. Autonomous AI - uses all the capabilities of the previous stages plus directs and shapes the world around it (i.e., self-driving cars, assembly line production control)

5. Artificial General Intelligence - AI functions similar to the human brain and can perform any intellectual task.

The first two forms of AI are in evidence today and are utilized in adaptive learning software. The next two are still in their early development stages. The fifth, which is the most sophisticated form of AI, is in discussion stages, with some predicting it will be available as early as 2030 and others indicating it will not be perfected until later in the 2040s and beyond. The fact is that there are "no known algorithms for artificial general intelligence or a clear route to get there" (Lee, 2018, p. 142). However, recent advances being made with AI should not be underestimated, especially regarding algorithms that take on characteristics of machine or deep learning. Unlike many earlier forms of AI that depended upon hundreds of thousands of lines of code to predict something, new advances enable AI algorithms to learn from within themselves. Lee (2018) also cautions not to think of the development of AI as simply computer coding but rather as a new form of intellectual "electricity" that will support all forms of personal and commercial endeavors.

Steven Strogatz, professor of mathematics at Cornell University, has raised the possibility that AI has evolved to the point where it has the beginnings of insight. He described AlphaZero, a generic algorithm that mastered chess and Go with absolutely no knowledge of the games beyond their basic rules, and within a matter of hours of playing against itself had become the best player, human or otherwise, we have ever seen. Here is an excerpt from Strogatz's essay:

Computer chess has come a long way over the past twenty years. In 1997, I.B.M.'s chessplaying program, Deep Blue, managed to beat the reigning human world champion, Garry Kasparov, in a six-game match. In retrospect, there was little mystery in this achievement. Deep Blue could evaluate 200 million positions per second. It never got tired, never blundered in a calculation and never forgot what it had been thinking a moment earlier. For better and worse, it played like a machine, brutally and materialistically. It could outcompute Mr. Kasparov, but it couldn't outthink him. ...

These principles, which have been refined over decades of human grandmaster experience, are programmed into the engines as complex evaluation functions that indicate what to seek in a position and what to avoid: how much to value king safety, piece activity, pawn structure, control of the center, and more, and how to balance the trade-offs among them. Today's chess engines, innately oblivious to these principles, come across as brutes: tremendously fast and strong, but utterly lacking insight. 
All of that has changed with the rise of machine learning. By playing against itself and updating its neural network as it learned from experience, AlphaZero discovered the principles of chess on its own and quickly became the best player ever. Not only could it have easily defeated all the strongest human masters - it didn't even bother to try - it crushed Stockfish, the reigning computer world champion of chess. In a hundred-game match against a truly formidable engine, AlphaZero scored twenty-eight wins and seventytwo draws. It didn't lose a single game.

Most unnerving was that AlphaZero seemed to express insight. It played like no computer ever has, intuitively and beautifully, with a romantic, attacking style. It played gambits and took risks....

AlphaZero won by thinking smarter, not faster; it examined only 60 thousand positions a second, compared to 60 million for Stockfish. It was wiser, knowing what to think about and what to ignore. By discovering the principles of chess on its own, AlphaZero developed a style of play that "reflects the truth" about the game rather than "the priorities and prejudices of programmers." (Strogatz, 2018)

Adaptive learning and analytics are already being significantly integrated with Internet and business AI. The integration of learning analytics is greatly enhanced based on student responses to prompts, questions, quizzes, and increasingly on less structured assessments, such as essay writing. Combining these with the ongoing collections of student demographic, academic performance, and other information provides an extensive learning analytics database upon which students and faculty can depend for recommendations as they proceed through a course of study. Over the next decade or so, the software supporting these types of applications will grow in sophistication, especially when integrated with supercloud data depositories that will extend academic programs, curriculum, and coursework beyond individual colleges and institutions. In the 2030s and beyond, AI-based adaptive learning will come to dominate much of the instruction in higher education.

\section{What Is the Academy to Do?}

Joseph E. Aoun is the president of Northeastern University and author of Robot Proof, Higher Education in the Age of Artificial Intelligence. In looking at the future of higher education and the changes that will occur as a result of digital technology and especially AI, Aoun acknowledged American colleges and universities as among the fullest expressions of human culture ever evolved and perhaps the most effective institutions for intellectual advancement ever developed. However, he went on to caution that if they fail to respond creatively and deliberately to the technological challenges that they face, "they will wither into irrelevance" (Aoun, 2017, p. 12). In considering a future dominated by advanced technologies, educators should seek to integrate technology into a comprehensive plan that addresses other major issues that they will be facing in the not too distant future.

Clayton Christensen, Harvard Business School Professor and author of The Innovator's Dilemma, during a speech at a Higher Education Summit in 2017, spoke at length about disruption theory and discussed its application to colleges and universities. Higher education, he explained, was among the industries that "for several centuries was not disrupted," but "online learning has put a kink in that." He predicted that half of American universities would close or go bankrupt within 10 to 15 years. He went on to say that "technology itself is never the disruptor, a new business model is. But it is technology that enables the new business model to coalesce, and that's what is happening in higher education now" (Hess, 2018). 
Drew Faust, the former president of Harvard University, in a message to the World Economic Forum in 2015, described three major forces that will shape the future of higher education:

1. the influence of technology

2. the changing shape of knowledge

3. the attempt to define the value of education.

She went on to extol the facilities that digital technology and communications will provide for teaching, learning, and research. She foresees great benefits in technology's ability to reach masses of students around the globe and to easily quantify large databases for scaling up and assessment purposes. On the other hand, she made it clear that "residential education cannot be replicated online" and stressed the importance of physical interaction and shared experiences.

On the nature of knowledge, she stated that the common organization of universities by academic departments may disappear because "the most significant and consequential challenges humanity faces" require investigations and solutions that are flexible and not necessarily discipline specific. Doctors, chemists, social scientists, and engineers will work together to solve humankind's problems.

On defining value, she accepts that quantitative metrics are now evolving that can assess the importance of meaningful employment. She also believes that higher education provides something very valuable: It gives people "a perspective on the meaning and purpose of their lives." Furthermore, it is not possible to quantify this type of student outcome. She concluded that

so much of what humanity has achieved has been sparked and sustained by the research and teaching that take place every day at colleges and universities, sites of curiosity and creativity that nurture some of the finest aspirations of individuals and, in turn, improve their lives - and their livelihoods. As the landscape continues to change, we must be careful to protect the ideals at the heart of higher education, ideals that serve us all well as we work together to improve the world. (Faust, 2015)

While Faust presented three key elements in higher education's future, it is the interplay of these elements that will become most crucial in predicting its future. Will technology drive the shape of knowledge and the definition of value, or will it be the other way around? Technocentrists see technology as the driver while others who look at higher education holistically see technology as a tool serving the needs of the other elements.

Aoun, Christensen, and Faust are all respected and accomplished individuals in American higher education. Common to their predictions of the future is the role technology will play. Aoun and Christensen have concerns about whether and if higher education can adjust and adapt to a new world order dominated by technology. Faust holds out hope that colleges will adjust and continue to function and "protect the ideals that have served us well." Most of those in higher education, and especially the faculty, like to think that Faust has it right. There will be adjustment and accommodation to technology and the academy will go on. However, there are dark clouds on the horizon driven especially by financial realities as well as technological and economic competition. In addition, the academy is squarely in the crosshairs of political factions in this country and is seen as a bastion of liberal philosophy that needs to be reined in. While there is support from progressive-minded government policy makers, there is also opposition from the other side of the political spectrum, where calls for funding contraction are already in evidence. 
In the United States during the past 20 years, there has been a loud, sustained call for more accountability and assessment as policy makers and the public question whether colleges and universities are as effective as they should be. The nonprofit public higher education sector where the majority of American college students are enrolled has seen a signifcant shift in funding away from government subsidy to student tuition. Contingent faculty, especially lower paid adjuncts, now teach the majority of all postsecondary courses. It is not by accident that public higher education systems have emerged (along with for-profit institutions) as among the most prolific in developing online education programs. They were moved to do so in order to meet student demand and also because of increasing competition from the other sectors, especially the for-profit institutions. Increasing enrollments and stagnant state-government subsidies also moved many public systems to adopt online instructional technology in hopes of stabilizing costs, especially for capital and campus-building projects. As we approach the 2020s, practically all segments of higher education (nonprofit, private, public, and for-profit) have embraced online technology as critical for their academic programs. However, what has been accomplished to date may not be enough to sustain what is coming in the years ahead. We are already seeing closures, mergers, and consolidations like never before.

The United States Education Department's National Center for Education Statistics shows that the number of colleges and universities eligible to award federal financial aid reached their peak in 2012 with 7,416 institutions. Due to closures, mergers, and consolidations, the number had declined to 6,760 , or $9 \%$, by 2016 . The vast majority of colleges that closed were in the for-profit private sector (Lederman, 2017). However during the past two years, the nonprofit private sector and the public sector have also seen a significant number of closures. Since 2016, 170 colleges have announced closures, mergers, or consolidations. Of these, 71 were private, for-profit; 63 were private, nonprofit; and 36 were public colleges (Education Dive Staff, 2019). Most of the private, nonprofits were small liberal arts colleges and were tuition driven with modest endowments. The publics were mostly in the states of Georgia, Wisconsin, and Connecticut, where major restructuring of public higher education has been underway. In Wisconsin, for instance, all 13 community colleges were restructured as extension centers under the auspices of the Wisconsin system's senior colleges. In Connecticut, all 12 community colleges are in the process of being consolidated into one institution. These changes were made strictly because of existing financial exigencies. The future does not look brighter, and more governing boards in all higher education sectors will be facing serious finanical pressures. Closures will be more common, and those colleges and universities that continue will have to find more cost-efficient ways of offering an education. Policy makers will look to technology to effect savings in all aspects of the higher education enterprise, including instruction, advising, counseling, administrative services, and research. It is also likely that some colleges and universities, especially those publicly funded, will grow significantly in terms of enrollments. An institution such as the University of Southern New Hampshire, which grew from 8,000 students in 2008 to over 122,000 by 2018 by adopting a new online education technology model, is being closely watched by educational policy makers in other states (Blumenstyk, 2018).

The critical questions to be answered by the academy are how to adapt to and address the new technologies. Full-time faculty will likely see their ranks reduced. Those that primarily teach in colleges and universities may have to adjust to a tutor role rather than develop and teach their own content via their own pedagogical practices. Students may increasingly select off-the-shelf courses, perhaps developed at another college, university, or by a private supplier. Faculty researchers may be engaged in very large-scale projects that involve multiple partners in the academy and in private industry. It is also possible that the lead researchers may be algorithms in 
an AI laboratory. The comments of Mohammed AlQuraishi, the biologist who at the beginning of this article had a feeling of melancholy when he saw an AI application sweep away the competition in the Critical Assessment of Structure Prediction Competition, may portend the feelings of many teaching and research faculty. Other aspects of the academy likewise will be affected by AI. Library holdings will be moved to all-electronic access, with AI speeding searches for materials and delivering the same within minutes on mobile devices. Academic advisers and counselors will see their roles reduced to offering assistance only in deeply personal situations where the human side of their work is most important. All academic advisement regarding course requirements, majors, and careers will be done via AI applications. Administrative functions will be consolidated and centralized with supercloud services for admissions, registration, financial aid, bursaring, and purchasing. Large public university systems will see many of these services centralized, and the need for presidential, vice presidential, and other administrative operations at the local campus level will be significantly reduced. The question is whether higher education will adjust to and accommodate the new world order where technology will provide foundational services. Many educators will feel a loss of purpose in light of the fact that their expertise will be overshadowed by AI software. Younger and newer educators will take their places, accept the new order, and work within it to make it successful; but the period of transition will be tense, if not painful. Educators will have to come to see technology as primary partners in the higher education enterprise, as have counterparts in private industry (McAfee \& Brynjolfsson, 2017, p. 15). As Auon, Christensen, and Faust alluded to earlier, the issue is not just that the technology changes but how people change in response to the technology. This will be higher education's challenge over the next two decades and beyond.

It would be easy to dismiss negative speculation as just crying wolf and assume that our colleges and universites will weather any possible storm well. I hope this is the case, but it is not likely. Much of higher education, with the exception of the heavily endowed colleges, are in difficult financial times; closures, mergers, and consolidations are already happening. It is difficult to see how we will move gracefully beyond the financial exigencies already in evidence. The federal government is the one institution that might be able to ease this situation, but its debt has grown considerably in the past five years, and there does not appear to be the political wherewithal to address it. It is unlikely that the federal government will come to the rescue of higher education, especially since there will be pressures from other government services, such as health and social welfare. Unemployment will permeate many endeavors. In addition, in the AI arena, there will be severe competition between the United States and the People's Republic of China for dominance. Right now seven companies are making the greatest investments in AI development (Lee, 2018, p. 91). Four (Google, Amazon, Microsoft, and Facebook) are based in this country, and three (Baidu, Alibaba, and Tencent) are based in China. The Chinese government is pouring huge amounts of capital into developing its AI capabilites and will very possibly take the lead in this area in the not too distant future. Higher education will be directed if not forced to respond to this AI challenge. It might be beneficial for administrators, faculty, and researchers to consider how they might partner with centers of AI and adaptive learning that exist in the corporate sector (Dziuban, Colm, Johnson, \& Moskal, 2017). Technology companies are proliferating and generally welcome collaborators for their products and services. This was the conclusion that the biologist and chemist reached in the DeepMind vignette that opened this article.

A few years ago, a young associate professor approached me after I had given a talk about online education. Our discussion centered on the future of higher education, and she asked if I thought that in 10 years she would be out of a job. My answer to her was that she would not be 
displaced anytime soon but that the way she teaches would change. I stand by that comment. Educators must be alert to new technologies and adjust, change, and adapt those that may benefit their students. These changes are best implemented through carefully planned and developed projects, programs, and initiatives rather than by disruptive sudden upheavals. It is critical that colleges and universities be open to changing and adapting. Higher education must use technologies that are beneficial, question those that are not, but most importantly not ignore them. In addition, it would be wise for the academy to partner with those private companies that can bring financial resources and expertise to the issues that AI will usher in. The challenges are formidable. Joseph Aoun, referenced earlier, commented as follows: "If technology can replace human beings on the job, it will. Preventing business owners from adopting a labor-saving technology would require modifying the basic incentives built into the market economy" (Aoun, 2017, p. 46).

The Future of Life Institute (2015) initiated an open letter entitled Research Priorities for Robust and Beneficial Artificial Intelligence expressing the same concerns about AI development as described above by Aoun and others. The open letter was signed by Stephen Hawking, Elon Musk (founder of SpaceX and Tesla Motors), Steve Wozniak, (cofounder of Apple), and many of the world's top computer scientists. It also was a call for more dialogue among all parties involved with AI development. Their concerns reflect the concerns of humanity over our ability to control the advancements of AI.

In A Christmas Carol, by Charles Dickens, the miserly Ebenezer Scrooge is visited on Christmas Eve sometime in the 1840s by the ghost of his former business partner Jacob Marley as well as the Ghosts of Christmases Past, Present, and Future. The Ghosts take a reluctant Scrooge on a time-travel voyage to see the people, places, and things that have mattered and will matter to him. The past reflects memories of childhood, love, and career. The present has some joys but also illuminates the stark realities of London's poor, its orphans, its prisons, and its workhouses. The future is dark and haunting. Scrooge sees the empty chair where Bob Cratchit's lame son, Tiny Tim, would normally sit. The visit to the future ends as Scrooge faces his own mortality in the form of a tombstone inscribed with his name. He asks the Ghost,

"Before I draw nearer to that stone to which you point, answer me one question. Are these the shadows of the things that Will be, or are they shadows of things that May be..?"

The Ghost continued to point downward to the grave by which it stood.

"Men's courses will foreshadow certain ends, to which, if persevered in, they must lead," said Scrooge. "But if the courses be departed from, the ends will change. Say it is thus with what you show me!" (Dickens, 1843)

\section{Special Acknowledgment}

I would like to thank my colleagues Peter Shea, Chuck Dziuban, and Karen Swan for their thoughts and suggestions on earlier drafts of this article. 


\section{References}

AlQuraishi, M. (2018, December 9). AlphaFold @ CASP13: “What just happened?" (Blog post). Retrieved from https://moalquraishi.wordpress.com/2018/12/09/alphafold-casp13-what-justhappened/

Aoun, R. E. (2017). Robot proof: Higher education in the age of artificial intelligence. Cambridge, MA: The MIT Press.

Arntz, M., Gregory, T., \& Zierahn, U. (2016, May14). The risk of automation for jobs in OECD countries: A comparative analysis. OECD Social, Employment, and Migration Working papers, No. 189. Retrieved from https://www.oecd-ilibrary.org/docserver/5jlz9h56dvq7en.pdf

Berriman, R., \& Hawksworth, J. (2017). Will robots steal our jobs? The potential impact of automation on the UK and other major economies. PwC. Retrieved from https://www.pwc.co.uk/economic-services/ukeo/pwcukeo-section-4-automation-march-2017v2.pdf

Blumenstyk, G. (2018, November 11). Meet the new mega university. The Chronicle of Higher Education. Retrieved from https://www.chronicle.com/article/Meet-the-New-MegaUniversity/245049

Carr, N. (2014). The glass cage: Automation and us. New York: W.W. Norton and Company.

Dziuban, C., Moskal, P. \& Hartman, J. (2016, September 30). Adapting to learn, learning to adapt. ECAR Research Bulletin. Retrieved from https:/library.educause.edu/resources/2016/9/adapting-to-learn-learning-to-adapt

Dziuban, C., Colm, H., Johnson, C. \& Moskal, P. (2017, December 18). An adaptive learning partnership. EDUCAUSE Review, Retrieved from https://er.educause.edu/articles/2017/12/an-adaptive-learning-partnership

Dziuban, C., Moskal, P., Parker, L., Campbell, M., Colm, H., \& Johnson, C. (2018, September). Adaptive learning: A stabilizing influence across disciplines and universities. Online Learning Journal, 22(3). Retrieved from https:/olj.onlinelearningconsortium.org/index.php/olj/article/view/1465/399

Education Dive Staff. (2019, January 29). How many colleges and universities have closed since 2016? Education Dive. Retrieved from https:/www.educationdive.com/news/tracker-collegeand-university-closings-and-consolidation/539961/

Faust, D. (2015). Three forces shaping the university of the future. World Economic Forum. Retrieved from https://agenda.weforum.org/2015/01/three-forces-shaping-the-university-ofthe-future/

Ford, M. (2015). The rise of the robots: Technology and the threat of a jobless future. New York: Basic Books.

Frey, C. B., \& Osborne, M. A. (2013, September 17). The future of employment: How susceptible are jobs to automation. Oxford Martin Programme on Technology and Employment. Retrieved from https://www.oxfordmartin.ox.ac.uk/downloads/academic/The_Future_of_Employment.pdf

Future of Life Institute. (2015). Research priorities for robust and beneficial artificial intelligence: An open letter. Retrieved from http://futureoflife.org/AI/open_letter 
Green, K. (2015). The 2015 campus computing survey. Encino, CA: The Campus Computing Project. Retrieved from http://www.campuscomputing.net/item/2015-campus-computing-survey-0

Harari, Y. N. (2017). Homo deus: A brief history of tomorrow. New York: HarperCollins Publishers. Harari, Y. N. (2017). 21 lessons for the 21st century. New York: Speigel \& Grau.

Hess, A. (2018, August 30). Harvard Business School professor: Half of American colleges will be bankrupt in 10 to 15 years. CNBC. Retrieved from https://www.cnbc.com/2018/08/30/hbsprof-says-half-of-us-colleges-will-be-bankrupt-in-10-to-15-years.html

Lederman, D. (2017, July 19), The dulling of higher ed begins. Inside Higher Ed. Retrieved from: https://www.insidehighered.com/news/2017/07/19/number-colleges-and-universities-dropssharply-amid-economic-turmoil

Lee, K. F. (2018). AI super-powers: China, Silicon Valley, and the new world order. Boston: Houghton Mifflin Harcourt.

Markoff, J. (2013, April 4). Essay-grading software offers professors a break. New York Times. Retrieved from https://www.nytimes.com/2013/04/05/science/new-test-for-computersgrading-essays-at-college-level.html

McAfee, A., \& Brynjolsson, E. (2017). Harnessing our digital future: Machine platform crowd. New York: W.W. Norton \& Company.

Metz, C. (2019, February 5). Making new drugs with a dose of artificial intelligence. The New York Times. Retrieved from https://www.nytimes.com/2019/02/05/technology/artificialintelligence-drug-research-deepmind.html

Moskal, P., Carter, D., \& Johnson, D. (2017, January 4). 7 things you should know about adaptive learning. EDUCAUSE ELI. Retrieved from https://library.educause.edu/resources/2017/1/7things-you-should-know-about-adaptive-learning

Picciano, A. G. (1994). Computers in the schools: A guide to planning and administration. New York: Merrill/Macmillan.

Seaman, J., Allan, E., \& Seaman, J. (2018). Grade increase: Tracking distance education in the United States. Needham, MA: Babson College Survey Research Group. Retrieved from http://www.onlinelearningsurvey.com/highered.html

Schlender, B. (1999, May 24). Larry Ellison Oracle at Web Speed: "The Internet changes everything," and the CEO of Oracle is living proof. Fortune Magazine. Retrieved from http://archive.fortune.com/magazines/fortune/fortune archive/1999/05/24/260276/index.htm

Smith, T. (2018, June 30). More states opting to 'robo-grade' student essays by computer. NPR. Retrieved from https://www.npr.org/2018/06/30/624373367/more-states-opting-to-robograde-student-essays-by-computer

Strogatz, S. (2018, December 26). One giant step for a chess-playing machine. New York Times. Retrieved from https://www.nytimes.com/2018/12/26/science/chess-artificialintelligence.html

Wan, T. (2018, August 21). Knewton’s business attracts new \$25M in funding. EdSurge. Digital Learning in Higher Ed. Retrieved from https://www.edsurge.com/news/2018-08-21-knewtons-new-business-attracts-new-25m-in-funding-but-some-things-don-t-change 